\title{
http://bjas.journals.ekb.eg \\ Study of the Relation between Plasma PTX3 Levels and Preclinical Atherosclerotic Cardiovascular Complications in Type 2 Diabetic Patients A.M.El-badawy, R.M.Omar, M.M.S.El-Sayed, A.M.Abdel Maksoud and A.H.El-sayed Internal Medicine Dept., Faculty of Medicine, Benha Univ., Benha, Egypt E-Mail:ahmed_shahin33@icloud.com
}

\begin{abstract}
Type 2 diabetes is contemporarily a major social and epidemiological problem and among others is a strong risk factor for cardiovascular diseases. Pentraxin 3 a potential early biomarker of the atherrosclerosis, is an acute phase reactant produced by the peripheral tissues where the inflammation takes place. to assess PTX3 plasma levels in metabolic syndrome patients compared to control subjects and their potential associations with anthropometric and clinical components of the syndrome as well as with carotid artery intima-media thickness (cIMT), a marker of subclinical atherosclerosis. This study was conducted on 58 type 2 diabetic patients( 34 men and 24 women ) as well as 30 age and sex matched non diabetic control subjects (12 men and 18 women ) the following tests were done FBS, lipid profile (Total serum cholesterol, triglyceride level and HDL cholesterol level). The LDL cholesterol level was estimated .In addition, we performed basic biochemical blood analysis (ALT,AST,CBC and TSH), Hemoglobin A1c and Plasma PTX3. Mean plasma PTX3concentration turned out to be significantly higher in patients with history of myocardial infarction, CABG and PCI $(\mathrm{p}=0.01)$. PTX3 was associated with outcomes in acute MI patients. PTX3 was associated with fatal events, and adverse clinical outcomes in heart failure patients.
\end{abstract}

Keywords: Plasma PTX3 levels, Atherosclerotic cardiovascular; Type 2 diabetic patients.

\section{Introduction}

The elements of the innate immune response, such as e.g.C-reactive protein (CRP) and recently pentraxin 3 (PTX3), have been examined as potential early biomarkersof the atherosclerotic process. PTX3 belongs to the pentraxin protein family, which has been divided into two groups on the basis of the primary structure of the subunit. CRP and serum amyloid P (SAP) belong to the short pentraxins, whereas PTX3is classified as the long one having pentameric cyclic structure [1].

PTX3 has emerged as a key acute-phase protein associated with inflammation in cardiovascular disorders, including heart failure,atherosclerosis, acute coronary syndromes, and peripheral vascular diseases. More importantly the predictive value of PTX3 appears to be independent of other risk factors including other markers of the same superfamily such as CRP. The rapid increase of PTX3 plasma levels during cardiovascular events as a consequence of rapid synthesis by various cell types supports the idea that PTX3 could bean early indicator of the activation of both immune and inflammatory responses [2]

Atherosclerosis is a common macrovascular complication among patients with type 2 diabetes mellitus and is a major cause of multiorgan damage. It is often present at the time of diabetes diagnosis after the vessels has been exposed to chronic hyperglycemia during the prediabetic phase. Detection of diabetic ASCVD during its initial stages provides the opportunity for early therapeutic interventions to prevent or delay the onset of complications and improve outcomes [3].
Although cholesterol accumulation intimal layer is the major pathological feature of atherogenesis, growing evidence suggests that the inflammatory state represents the major detrimental factor for the progression of atherosclerosis both in young and in elderly subjects. In fact, the earliest stage of atherosclerotic damage is characterized by infiltration of macrophages and T-lymphocytes, which are progressively activated during the course of the damage. Based on the kind of cell phenotype being recruited (macrophages and vascular cells), which is known to produce PTX3, this protein was investigated as a potential modulator of atherosclerosis [4].

PTX3 has emerged as a key acute-phase protein associated with inflammation in cardiovascular disorders, including heart failure,atherosclerosis, acute coronary syndromes, and peripheral vasculardiseases. More importantly the predictive value of PTX3 appears to beindependent of other risk factors including other markers of the samesuperfamily such as CRP. The rapid increase of PTX3 plasma levelsduring cardiovascular events as a consequence of rapid synthesisby various cell types supports the idea that PTX3 could bean early indicator of the activation of both immune andinflammatory responses [2].

The aim of this study was to assess PTX3 plasma levels in metabolic syndrome patients compared to control subjects and their potential associations with anthropometric and clinical components of the syndrome as well as with carotid artery intima-media thickness (cIMT), a marker of subclinical atherosclerosis. 
Aiming at tracing the early inflammatory markers of diabetic ASCVD, our study involved estimation of the levels of long PTX3as a novel marker of the endothelial dysfunction and preclinical atherosclerosis in four groups of participants. There was two groups of diabetic patients, with group I comprising diabetic patients with no ASCVD and group II comprising diabetic patients with ASCVD.

\section{Patients and methods \\ 2.1 patients}

This study was conducted on 58 type 2 diabetic patients(34 men and 24 women ) as well as 30 age and sex matched non diabetic control subjects (12 men and 18 women ) with age ranged from 18-75 year old. Diabetic patients were recruited from those attending the Outpatient diabetes and neurology clinics in Benha university hospitals .The duration of the study was 6 months from February to July 2018. Diagnosis of diabetes was done according to ADA criteria $(\mathrm{FBG} \geq 126 \mathrm{mg} / \mathrm{dl}, 2 \mathrm{~h}-\mathrm{PPG} \geq 200$ $\mathrm{mg} / \mathrm{dl}$ or random blood glucose $\geq 200 \mathrm{mg} / \mathrm{dl}$ plus classic symptom of diabetes or $\mathrm{HbA1C} \geq 6.5$ ) [5].

Diabetic patients $(n=58)$ were classified into 2 groups: (group I) includes 28 type 2 diabetic patients without manifest atherosclerotic cardiovascular disease and group II includes 30 patients with established atherosclerotic cardiovascular disease .

Group I patients $(n=28)$ were classified into 2 subgroups:

Subgroup Ia,Diabetic patients with subclinical atherosclerosis $(n=20)$ and Subgroup $I b$ without subclinical atherosclerosis $(n=8)$.

Subclinical atherosclerosis was diagnosed by presence of one or more of the following : atherosclerotic plaques by ultrasound examination of the carotid artery,RWMA by $\mathrm{ECHO}, \mathrm{LVH}$ and preclinical ischemic ECG changes .

The control subjects included 30 age-and sexmatched non diabetic subjects: They were classified into 2 groups: 15 patients with established atherosclerotic cardiovascular manifestations(group III)and 15 healthy subjects (group IV)

The study was approved by ethical committee of the internal medicine department. A written informed consent was taken from each patient .

\subsection{Methods}

Thorough history and clinical examination were performed to every subject with special emphasis on:

1. Smoking

2. Duration of diabetes

3. Atherosclerotic cardiovascular manifestations namely history of myocardial infarction, ischemic heart disease,PCI, CABG, stroke

,TIAor peripheral artery disease)

4. Drugs received by the patients

5. Anthropometric and blood pressure

measurements were done.

Anthropometric parameters, namely height (m) and weight $(\mathrm{kg})$, were measured by standard methods and the body mass index (BMI) was calculated using Metric imperial BMI formula as weight lheight2 $(\mathrm{kg} / \mathrm{m} 2)$.

Waist circumference was measured at the end of expiration at the level of maximum waist narrowing(The narrowest diameter between the costal arch and the anterior superior iliac spine was measured).

Blood pressure was measured by using a standard mercury sphygmomanometer. Blood pressure was measured after at least $10 \mathrm{~min}$ of rest in the sitting position. Blood pressure measurement was repeated two more times at 2min intervals. The average of the 3 measurements was considered as blood pressure. Arterial hypertension was defined as a systolic blood pressure $\geq 130 \mathrm{mmHg}$ and/or a diastolic blood pressure $\geq 85 \mathrm{mmHg}$ or previous treatment with antihypertensive medications

The following Investigations were performed to every subject

\section{I-Laboratory}

Venous blood samples were withdraw from all participants in the morning after overnight12$\mathrm{h}$ fast and serum was extracted to assess the FBS , lipid profile (Total serum cholesterol, triglyceride level and HDL cholesterol level). The LDL cholesterol level was estimated .In addition, we performed basic biochemical blood analysis (ALT,AST,CBC and TSH), Hemoglobin A1c was determined using high-performance liquid chromatography (HPLC) and the outcome was expressed in National Glycohemoglobin Standarization Program/ Diabetes Control and Complications Trial units.

The estimated glomerular filtration rate (eGFR) per $1.73 \mathrm{~m} 2$ was calculated according to CKD-EPI formula (Chronic kidney diseaseEpidemiology collaboration equation) [6]

Urinary albumin creatinine ratio (UACR) was calculated as follows: 24- $\mathrm{h}$ urine collection was performed three times, and the average was taken as a representative of each participant. General urine analysis was performed in order to detect any infections of the urinary tract.

Serum aliquot was stored at less than -20C until assayed for plasma PTX3. The plasma PTX3 level was estimated using the quantitative sandwich enzyme immunoassay technique .A streptavidin coated plate is incubated with a biotinylated monoclonal antibody specific for PTX3. The plates are then washed and pretreated 
standards and samples are added to the wells. Any PTX3 present is bound by the immobilized biotinylated antibody. An enzyme-linked conjugate specific for PTX3 is added to the wells, and after another wash to remove any unbound conjugate, a substrate solution is added to the wells and color develops in proportion to the amount of PTX3 bound. The color development stops and the intensity of the color is measured [14].

Plasma PTX3 level was measured by using a commercial quantitative sandwich enzymelinked immunosorbent assays(ELISA) and kits were supplied from bioassay technology(QuantikineHuman PTX-3/TSG-14 Immunoassay DPTX 30,R\&D systems Inc., Minneapolis,USA.

The results of plasma PTX3 are available in the form of standard curves that were generated for each set of samples assayed and the results were expressed in $\mathrm{ng} / \mathrm{ml}$. For PTX-3, intra-assay and interassay coefficients of variation ranged from 3.8 to $4.4 \%$ and from 4.1 to $6.1 \%$, respectively (minimum detecTable concentration: $0.025 \mathrm{ng} / \mathrm{ml})$.

\section{II-ECG}

\section{III-Radiological}

All the study participants underwent a carotid B-mode ultrasound examination using GE vivid
7 to determine the combined thickness of the arterial intimal and medial layers, measured in the common carotid artery. The carotid arteries were interrogated using a high-resolution ultrasound system Esaote MyLab60 with a linear-array transducer operating at a frequency of 5,6 - 8,0 MHz. Measurement of the carotid intima-media thickness (CIMT) was conducted in accordance with the ultrasound scanning protocol recommended in the Mannheim IntimaMedia Thickness Consensus 2006 [7]

The carotid intima-media thickness (IMT) values less than $0.1 \mathrm{~cm}$ were considered normal , and values more than $0.1 \mathrm{~cm}$ reflects thickening of the intimal layer seen in atherosclerosis and has been validated as a measure of the risk for cardiovascular events and atherosclerotic disease burden [8].

Transthoracic echocardiography was performed in order to assess the systolic cardiac function by measuring the ejection fraction (EF) by the Simpson method. The assessment of diastolic function was conducted by the measurement of the E/A velocity ratio together with tissue Doppler imaging (TDI).

\section{Results}

Table (1) Basic clinical, lab and radiological characteristics of the study groups

\begin{tabular}{|c|c|c|c|c|c|c|}
\hline Parameters & G I $(n=28)$ & G II $(n=30)$ & GIII $(n=15)$ & GIV $(n=15)$ & TEST & P value \\
\hline males & $12(42.9 \%)$ & $22(73.3 \%)$ & $5(33.3 \%)$ & $7(46.7 \%)$ & $X^{2}=0.925$ & 0.30 \\
\hline females & $16(57.1 \%)$ & $8(26.7 \%)$ & $10(66.7 \%)$ & $8(53.3 \%)$ & & \\
\hline Smoking & 10 & 15 & 5 & 5 & $X^{2}=2.325$ & 0.33 \\
\hline $\begin{array}{l}\text { Mean age [years] }( \pm \\
\text { SD) }\end{array}$ & $50.8 \pm(8.3)$ & $52.9( \pm 7.1)$ & $53.6 \pm(7.5)$ & $52.2( \pm 3.8)$ & $\mathrm{F}=0.1325$ & 0.30 \\
\hline $\begin{array}{l}\text { Diabetes duration } \\
(y)( \pm \text { SD })\end{array}$ & $2.46(1.43)$ & $5.72(2.26)$ & - & - & $\begin{array}{l}\mathrm{T} \text { test } \\
=29.55\end{array}$ & 0.0001 \\
\hline BMI $[\mathrm{kg} / \mathrm{m} 2]( \pm \mathrm{SD})$ & $30.00 \pm(1.7)$ & $31 \pm(2.3)$ & $32.3 \pm(2.8)$ & $24.7 \pm(4.3)$ & $\begin{aligned} & \mathrm{F} \text { test } \\
= & 122.55\end{aligned}$ & $<0.001$ \\
\hline $\begin{array}{l}\text { Waist } \\
\text { circumference } \\
(\text { Male })(\mathrm{cm}\end{array}$ & $108 \pm(7.5)$ & $111 \pm(3.9)$ & $\begin{array}{l}117.6 \pm \\
(5.8)\end{array}$ & $98 \pm(11.5)$ & $\begin{array}{l}\text { F test } \\
=5.55\end{array}$ & $<0.01$ \\
\hline $\begin{array}{l}\text { Waist } \\
\text { circumference } \\
\text { Female }\end{array}$ & $98(7.5)$ & $100(6)$ & $102(6)$ & $85(7.5)$ & $\begin{array}{l}\text { F test } \\
=6.55\end{array}$ & \\
\hline SBP mmHg & $\begin{array}{l}138.6 \pm \\
(14.33)\end{array}$ & $148 \pm(10.8)$ & $\begin{array}{l}150.4 \pm \\
(11.8)\end{array}$ & $\begin{array}{l}109.3 \pm \\
(9.31)\end{array}$ & $\begin{array}{c}\text { F test } \\
=16.55\end{array}$ & 0.010 \\
\hline DBP mmHg & $75 \pm(8.35)$ & $81.4 \pm(9.8)$ & $100.8 \pm(7.9)$ & $69 \pm(7)$ & $\begin{array}{c}\text { F test } \\
=16.55\end{array}$ & 0.0048 \\
\hline $\begin{array}{l}\mathrm{eGFR}^{*}[\mathrm{ml} / \mathrm{min} / \\
1.73 \mathrm{~m} 2]( \pm \mathrm{SD})\end{array}$ & $55.3 \pm(30.1)$ & $\begin{array}{l}49.3 \pm \\
(20.5)\end{array}$ & $\begin{array}{l}42.5 \pm \\
(19.8)\end{array}$ & $\begin{array}{c}104.3 \pm \\
(12.9)\end{array}$ & $\begin{array}{l}\text { F test } \\
=60.55\end{array}$ & 0.001 \\
\hline HbA1c $[\%]( \pm$ SD $)$ & $7.5(1.2)$ & $8.9(0.82)$ & $\begin{array}{c}5.433 \pm \\
(0.34)\end{array}$ & $5.2(0.67)$ & $\begin{aligned} & \text { F test } \\
= & 244.55\end{aligned}$ & 0.001 \\
\hline $\begin{array}{l}\text { HDL Cholesterol } \\
{[\mathrm{mg} / \mathrm{dl}]( \pm \text { SD) male }}\end{array}$ & $43 \pm(5.5)$ & $39 \pm(6)$ & $33.3 \pm(6.6)$ & $58 \pm(5)$ & $\begin{array}{l}\mathrm{F} \text { test } \\
=8.55\end{array}$ & 0.05 \\
\hline
\end{tabular}




\begin{tabular}{|c|c|c|c|c|c|c|}
\hline \multicolumn{7}{|l|}{ Table (1) Continue } \\
\hline $\begin{array}{l}\text { HDL Cholesterol } \\
{[\mathrm{mg} / \mathrm{dl}]( \pm \text { SD })} \\
\text { female }\end{array}$ & $53 \pm(5.8)$ & $33 \pm(6)$ & $39 \pm(6)$ & $59 \pm(6)$ & $\begin{array}{l}\text { F test } \\
=9.55\end{array}$ & \\
\hline LDL $[\mathrm{mg} / \mathrm{dl}]( \pm \mathrm{SD})$ & $125.9 \pm(8.1)$ & $\begin{array}{c}155.8 \pm \\
(8.5)\end{array}$ & $\begin{array}{c}160.3 \pm \\
(31.2)\end{array}$ & $98.3 \pm(10.2)$ & $\begin{array}{c}\mathrm{F} \text { test } \\
=42.55\end{array}$ & 0.001 \\
\hline $\begin{array}{l}\text { Triglycerides }[\mathrm{mg} / \mathrm{dl}] \\
( \pm \text { SD })\end{array}$ & $\begin{array}{c}212.3 \pm \\
(85.2)\end{array}$ & $285.3 \pm(60)$ & $\begin{array}{c}260.3 \pm \\
(49.9)\end{array}$ & $161.3 \pm(11)$ & $\begin{array}{l}\text { F test } \\
=62.55\end{array}$ & 0.001 \\
\hline $\begin{array}{l}\text { PTX3 [ng/ml] ( } \pm \\
\text { SD) }\end{array}$ & $1.88 \pm(1.4)$ & $3.93 \pm(2.2)$ & $3.63 \pm(1.8)$ & 1.20 & $\begin{array}{l}\text { F test } \\
=52.55\end{array}$ & 0.001 \\
\hline $\begin{array}{l}\text { CCA ITM mean } \\
{[\mathrm{cm}]( \pm \text { SD) }}\end{array}$ & $0.09(0.085)$ & $0.18(0.2)$ & $0.13(0.15)$ & $0.01(0.010)$ & $\begin{array}{l}\mathrm{F} \text { test } \\
=42.55\end{array}$ & 0.001 \\
\hline $\mathrm{EF}[\%]$ & $60 \pm(2.8)$ & $61.6 \pm(2.1)$ & $62.3 \pm(2.2)$ & $64 \pm(4.3)$ & $\begin{array}{l}\mathrm{F} \text { test } \\
=2.55\end{array}$ & 0.44 \\
\hline $\begin{array}{l}\text { Myocardial } \\
\text { infarction n [\%] }\end{array}$ & 0 & $14(46.7 \%)$ & $1(6.7 \%)$ & 0 & $\mathrm{X}^{2}=20.5$ & 0.04 \\
\hline Stroke n [\%] & 0 & $8(26.7 \%)$ & $4(26.7 \%)$ & 0 & $X^{2}=24.5$ & 0.02 \\
\hline CABG** $\mathbf{n}[\%]$ & 0 & $8(26.7 \%)$ & $1(6.7 \%)$ & 0 & $X^{2}=13.5$ & 0.05 \\
\hline RWMA & 16 & 18 & 10 & 0 & $X^{2}=0.42$ & 0.34 \\
\hline LVH & 16 & 20 & 12 & 0 & $X^{2}=0.62$ & 0.33 \\
\hline Medications & & & & 0 & $X^{2}=0.42$ & \\
\hline Antiplatelets & $14(51 \%)$ & 15 & 5 & & & \\
\hline ACEI\ARBS & $8(28.5 \%)$ & 5 & 5 & & & \\
\hline B Blockers & $3(10.7 \%)$ & 2 & 3 & & & \\
\hline Statin & $3(10.7 \%)$ & 8 & 2 & & & \\
\hline Antidiabetic drugs & & & & & & \\
\hline OAD & 20 & 16 & & & & \\
\hline Insulin & 12 & 18 & & & & \\
\hline
\end{tabular}

Table (2) Comparison between the mean value of PTX3among the studied groups

\begin{tabular}{cccccccc}
\hline Parameter & $\begin{array}{c}\text { GroupI } \\
\text { versus } \\
\text { Group II }\end{array}$ & $\begin{array}{c}\text { Group I } \\
\text { Versus } \\
\text { GroupIII }\end{array}$ & $\begin{array}{c}\text { Group II } \\
\text { versus } \\
\text { III }\end{array}$ & $\begin{array}{c}\text { Group I } \\
\text { versus } \\
\text { group IV }\end{array}$ & $\begin{array}{c}\text { Group II } \\
\text { versus } \\
\text { group IV }\end{array}$ & $\begin{array}{c}\text { Group III } \\
\text { Versus } \\
\text { group IV }\end{array}$ \\
\hline PTX3 & $\mathbf{t}$ & 10.88 & 9.753 & 0.7 & 5.25 & 11.65 & 16.01 \\
& $\mathrm{P}$ & $<0.01$ & $<0.01$ & $>0.05$ & $<0.05$ & $<0.001$ & $<0.001$ \\
\hline
\end{tabular}

PTX3 was significantly high in all patient groups compared to group IV. PTX3 was significantly high in diabetic patients with ASCVD (Group II) compared to diabetic patients without ASCVD (Group I) with $\mathrm{p}<0.01$.
Comparison of the mean value of PTX3 between group I vs III , group I vs IV , group II vs IV and group III vs IV was significant Comparison of the mean value of PTX3 between groups II and III was not significant

Table (3) Comparison of mean value of plasma PTX3 in group I patients according to UACR (diabetic patients without ASCVD) $(\mathrm{N}=28)$

\begin{tabular}{lccc}
\hline UACR & A1 versus A2 & A1 Versus A3 & A2 versus A3 \\
\hline PTX3 & $0.780 \mathrm{ng} / \mathrm{ml}( \pm 0.30)$ & $0.780 \mathrm{ng} / \mathrm{ml}( \pm 0.30)$ & $1.21 \mathrm{ng} / \mathrm{ml}( \pm 0.74$ \\
& $1.21 \mathrm{ng} / \mathrm{ml}( \pm 0.74)$ & $2.76 \mathrm{ng} / \mathrm{ml}( \pm 0.53)$ & $2.76 \mathrm{ng} / \mathrm{ml}( \pm 0.53$ \\
T test & 2.23 & 7.753 & 5.8 \\
P & $<0.05$ & $<0.001$ & $<0.001$ \\
\hline
\end{tabular}

In this group mean plasma PTX3 concentration was significantly high in patients with A2 protinurea and in patients with A3 protinurea compared to patients with A1 protinurea
Also mean plasma PTX3 concentration was significantly high in patients with A3 protinurea compared to patients with A2 protinurea. 
Table (4) Correlation between pentraxin 3 levels and risk factors in diabetic patients without ASCVD (study group I).

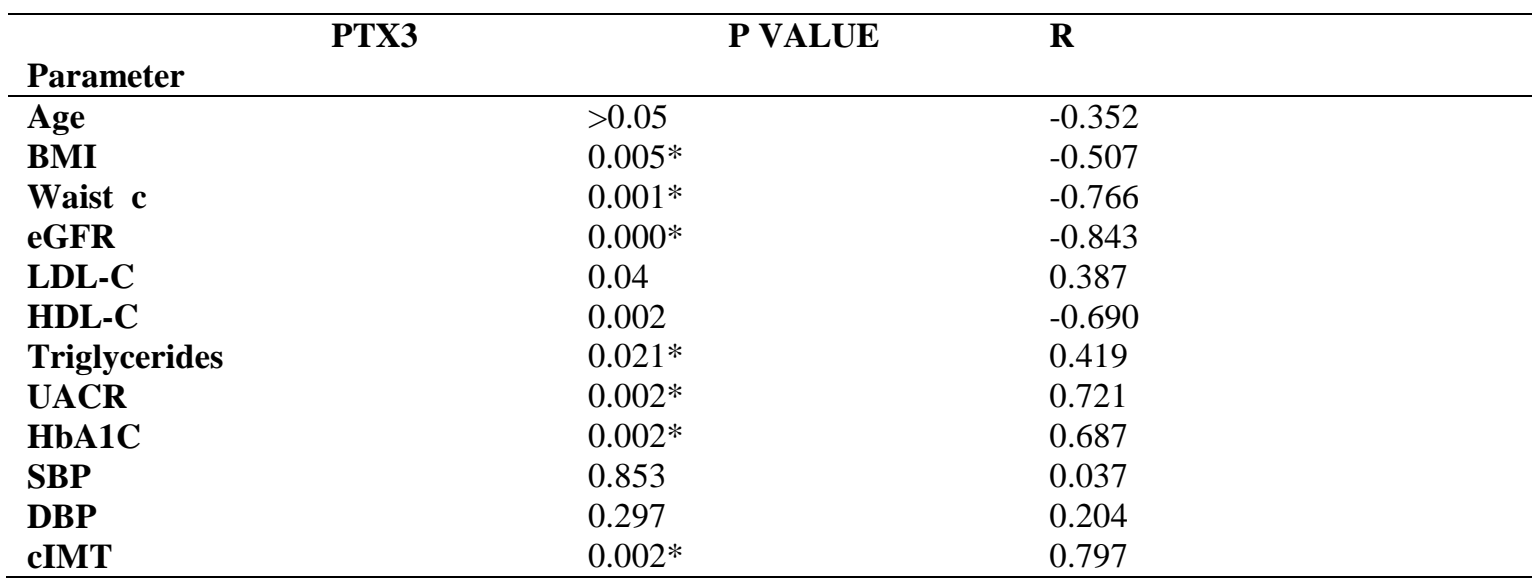

This Table shows :

1-a statistically significant positive correlation between PTX3 level and LDL-C( $\mathrm{p}=0.04, \quad \mathrm{Rho}=0.387), \quad \operatorname{HbA} 1 \mathrm{C}(\mathrm{p}=0.002$, Rho=0.687), UACR( $\mathrm{p}=0.002$, Rho $=0.721)$ and cIMT $(\mathrm{p}=0.002$, Rho=0.797).
2-There is a statistically significant negative correlation between PTX3 level and BMI, Waist c, HDL-C and eGFR.

3-There is no significant correlation between PTX3 level and BP

Table (5) Comparison of mean plasma PTX3 and analyzed parameters In study group II (n=30)

\begin{tabular}{|c|c|c|c|c|}
\hline Parameter & & PTX3 $(n=30)$ & $X^{2}$ & $\mathbf{P}$ \\
\hline \multirow[t]{2}{*}{ MI history } & with & $3.71 \pm 0.49$ & 11.33 & 0.01 \\
\hline & without & $2.03 \pm 0.51$ & & \\
\hline \multirow[t]{2}{*}{ CABG history } & with & $3.9( \pm 0.18)$ & 10.62 & 0.01 \\
\hline & without & $2.3( \pm 0.53)$ & & \\
\hline \multirow[t]{2}{*}{ PCI history } & with & $3.9( \pm .18)$ & 4.50 & 0.01 \\
\hline & without & $3.2( \pm 0.53)$ & & \\
\hline \multirow[t]{2}{*}{ Stroke } & with & $3.45 \pm .49$ & 2.22 & 0.05 \\
\hline & without & $3.01 \pm .57$ & & \\
\hline
\end{tabular}

Mean plasma PTX3concentration turned out to be significantly higher in patients with history of myocardial infarction, CABG and PCI $(\mathrm{p}=0.01)$ in groupII

Table(6) Multiple linear regression for the predictors of PTX3 among the studied groups. (N=88)

\begin{tabular}{lcccc}
\hline variable & B & sig & $\mathbf{9 5 \%}$ CI & $\mathbf{r}^{\mathbf{2}}$ \\
\hline cIMT $(\mathrm{cm})$ & 9.192 & $.000^{* * *}$ & $4.505-13.878$ & \\
UAE & .001 & $.038^{* * *}$ & $.000-.001$ & \\
BMI & .035 & .166 & $-.015-.084$ & \\
FBS & -.001 & .254 & $-.003-.001$ & 0.665 \\
e GFR & -.008 & .265 & $-.023-.006$ & \\
EF\% & -.012 & .409 & $-.041-.017$ & \\
\hline
\end{tabular}

This Table shows that c IMT ,UACR ,BMI and eGFR are considered strong predictors for high plasma PTX3 levels in diabetic ASCVD.

\section{Discussion}

Although cholesterol accumulation intimal layer is the major pathological feature of atherogenesis, growing evidence suggests that the inflammatory state represents the major detrimental factor for the progression of atherosclerosis both in young and in elderly subjects. In fact, the earliest stage of atherosclerotic damage is characterized by infiltration of macrophages and T-lymphocytes, which are progressively activated during the course of the damage. Based on the kind of cell phenotype being recruited (macrophages and vascular cells), which is known to produce 
PTX3, this protein was investigated as a potential modulator of atherosclerosis [4]

The plasma PTX3 concentration association with gender also has been noticed in a study done by abu Seman et al.,2013 which was performed on patients from Malaysia; however, the authors found lower concentration of plasma PTX3 in males to be associated with type 2 diabetes . Since males have a higher prevalence of type 2 diabetes and diabetic nephropathy, an association between plasma PTX3 and gender should be taken into consideration in future studies

In our study, Mean plasma PTX3 was significantly high in both diabetic groups compared to group IV Table (3)

In our study, Mean plasma PTX3 was significantly higher in uncontrolled diabetic patients and higher with increased diabetes duration .

Our results are in agreement with Wang and his colleagues (2016) who reported that serum pentraxin-3 concentration was significantly high in patients with $\mathrm{T} 2 \mathrm{DM}$ in comparison to control

Our study are in agreement with [9] who, showed that serum pentraxin-3 was significantly higher in diabetic patients compared to controls

Yuichi et al.,2018 also found that serum PTX3 level was significantly positively correlated with existence of diabetes, HbA1c $(\mathrm{r}=$ $0.379, \mathrm{P}<0.001 ; \mathrm{r}=0.431, \mathrm{P}<0.001)$.

Our results agree with [10]. They reported that there was significant positive correlation between pentraxin-3 and duration of diabetes, $\mathrm{HbA1c}$ and fasting blood sugar.

In study group I (T2DM without manifest ASCVD $) \quad(n=28)$ showed that PTX3 was significantly high in diabetic patients with subclinical atherosclerosis when compared to those without subclinical atherosclerosis. The difference of Duration of diabetes ,bl. Pressure ,BMI,W.C,lipid profile ,e GFR ,c IMT, ECG changes and left ventricular hypertrophy between both groups was significant.

As regard pentraxin 3 and $\mathrm{CKD}$ in diabetic patients, our results showed that mean plasma PTX3 concentration was significantly high in patients with A2 protinurea and in patients with A3 protinurea compared to patients with A1 protinurea

Also mean plasma PTX3 concentration was significantly high in patients with A3 protinurea compared to patients with A2 protinurea Table (6).

In our study, relation between pentraxin 3 and atherosclerosis risk factors could be inferred from Table 8 that shows that mean plasma PTX3 was significantly low in patients with BMI $\geq 30 \mathrm{~kg} / \mathrm{m}^{2}$ compared to those with BMI $25-29 \mathrm{~kg} / \mathrm{m}^{2}$
, significantly low in patients with waist circumference $\geq 94$ in male,$\geq 80$ in females compared to the ones with normal waist circumference

, significantly high in patients with LDL$c \geq 100$ compared to those with LDL-c $<100$

,significantly high in patients with $\mathrm{TG} \geq 150$ compared to the ones with $\mathrm{TG}<150$

and significantly high in patients with atherosclerosis in the carotid arteries(cIMT $\geq 0.1$ $\mathrm{cm}$ according to reference range compared to the ones without carotid atherosclerosis $(\mathrm{cIMT}<0.1 \mathrm{~cm})$

Our results was in accordance with data from a clinical study by Norata et al in a healthy Japanese population which found that PTX3 is inversely correlated with obesity and metabolic syndrome .

However, PTX3 levels did vary significantly by BMI category in MESA(Multi ethnic study of atherosclerosis) sample. PTX3 expression by adipose tissue and circulating levels have been reported to be higher in obese subjects than in normal-weight subjects [11].

In a small study of men under conditions of caloric restriction and bed rest, Bosutti et al.2008 also reported inverse associations of PTX3 levels with fat mass. [8] likewise found an inverse association of PTX3 levels with obesity in the Brunek Study and hypothesized that nutrition may play a role in regulation of PTX3 levels. These conflicting results may be attribuTable to differences in fat mass and distribution between the cohorts

Matsui et al.2010 hypothesized that the serum PTX-3 level might be useful for the early diagnosis of atherosclerosis and might be an easy way to diagnose the disease and determine its intensity, and they investigated whether or not there are any associations of the PTX levels with the presence and intensity of CAD in a group of sTable patients who were suspected of having CAD. The analysis of their data revealed that the serum PTX-3 levels were higher in the patients with $\mathrm{CAD}$ in comparison to the patients with a normal coronary vessel anatomy. In the patients with CAD, the PTX-3 values were found to be higher in the group of patients with $\geq 50 \%$ stenosis compared to the group of patients with $<50 \%$ stenosis.

In the Bruneck Study, PTX3 levels were found to be independently related to both carotid and femoral atherosclerosis and to manifest cardiovascular diseases mainly originating from unsTable plaques. Moreover, PTX3 level increased with the number of vascular beds involved in the atherosclerotic process [12]

In study conducted by Kotooka et al., Immunohistochemical staining of advanced atherosclerotic lesions revealed a strong 
expression of PTX3 on the surface of lumen as well as within the atherosclerotic plaque in animal models and in humans.

In study group II ,mean plasma PTX3 concentrations were significantly high in patients with history of myocardial infarction, CABG history and PCI history and that was in agreement with Dubin et al, who found associations of PTX3 with the risks of MI and combined CHD events. In subjects with sTable CHD, PTX3 was associated with the risks of allcause death and CVD events and Jenny et al who found in older adults free of clinical CVD in the CHS, PTX3 was associated with the risks of CVD-related and all-cause death independently from CVD risk factors.

Our findings agree with Latini ., who reported that PTX3 was associated with outcomes in acute MI patients. They found PTX3 was associated with fatal events, similar to Suzuki, who reported that PTX3 was associated with adverse clinical outcomes in heart failure patients. In addition, in patients with chronic kidney disease, PTX3 is reported to predict all-cause mortality[13].

\section{References}

[1] A. Mantovani., "The long pentraxin PTX3 in vascular pathology," Vascul. Pharmacol,Vol. 45(5), PP. 326-330, 2006.

[2] C. Garlanda, B. Bottazzi, A. Bastone, and A. Mantovani, "Pentraxins at the crossroads between innate immunity, inflammation, matrix deposition, and female fertility," Annu. Rev. Immunol, Vol. 23, PP. 337-366, 2005.

[3] M. Wei, S. P. Gaskill, S. M. Haffner, and M. P. Stern, "Effects of diabetes and level of glycemia on all-cause and cardiovascular mortality: the San Antonio Heart Study," Diabetes Care, Vol. 21(7), PP. 1167-1172, 1998.

[4] P. Libby, Y. Okamoto, V. Z. Rocha, and E. Folco, "Inflammation in atherosclerosis: transition from theory to practice," Circ. J, Vol. 74(2), PP. 213-220, 2010.

[5] A. D. Association, "Standards of medical care in diabetes-2016: summary of revisions," Diabetes Care, Vol. 39, no. Supplement 1, PP. S4-S5, 2016.

[6]A. S. Levey 1., "A new equation to estimate glomerular filtration rate," Ann. Intern. Med., Vol. 150, no. 9, PP. 604-612, 2009.

[7]M. W. Lorenz, M. Sitzer, H. S. Markus, M. L. Bots, and M. Rosvall, "Prediction of clinical cardiovascular events with carotid intimamedia thickness: A systematic review and meta-analysis-Response," Circulation, Vol. 116( 9), p. 318, 2007.

[8]A. Baragetti ., "Pentraxin 3 (PTX3) plasma levels and carotid intima media thickness progression in the general population," Nutr. Metab. Cardiovasc. Dis., Vol. 24(5), PP. 518-523, 2014.

[9]C. Salcini., "High plasma pentraxin 3 levels in diabetic polyneuropathy patients with nociceptive pain," Tohoku J. Exp. Med., Vol. 239(1), PP. 73-79, 2016.

[10]A. A. El Meligi, A. M. A. Hamid, M. A. Aziz, H. E. El Haddadd, M. F. Ishak, and E. M. Yousief, "Plasma long pentraxin 3 as a marker of endothelial dysfunction in early diabetic nephropathy," Egypt. J. Intern. Med., Vol. 25(3), p. 117, 2013.

[11]O. Osorio-Conles ., "Plasma PTX3 protein levels inversely correlate with insulin secretion and obesity, whereas visceral adipose tissue PTX3 gene expression is increased in obesity," Am. J. Physiol. Metab, Vol. 301(6), PP. E1254-E1261, 2011.

[12]A. S. Savchenko ., "Long pentraxin 3 (PTX3) expression and release by neutrophils in vitro and in ulcerative colitis," Pathol. Int., Vol. 61(5), PP. 290-297, 2011.

[13]R. Latini ., "Prognostic significance of the long pentraxin PTX3 in acute myocardial infarction," Circulation, Vol. 110(16), PP. 2349-2354, 2004.

[14]Bottazzi B .,Vouret-Craviari V.,Bastone A.,De Gioia L .,et al.,(1997).Multimer formation and ligand recognition PTX3 similarities and differences with the short pentraxins C-reactive protein and serum amyloid p .JBiol.Chem.272,32817-32823. 